\title{
Dynamic Hip Screw for the Treatment of Femoral Neck Fractures: A Prospective Study with 96 Patients
}

\section{Carlos Roberto Schwartsmann, ${ }^{1}$ Lucas Senger Jacobus, ${ }^{2}$ Leandro de Freitas Spinelli, ${ }^{3}$ Leonardo Carbonera Boschin, ${ }^{3}$ Ramiro Zilles Gonçalves, ${ }^{3}$ Anthony Kerbes Yépez, ${ }^{3}$ Rodrigo Py Gonçalves Barreto, ${ }^{4}$ and Marcelo Faria Silva ${ }^{5}$}

${ }^{1}$ Orthopaedics and Traumatology, Federal University of Health Sciences of Porto Alegre and Santa Casa de Misericordia of Porto Alegre, Rua Leopoldo Bier, 825/cj 403, 90620-100 Porto Alegre, RS, Brazil

${ }^{2}$ Department of Orthopaedics and Traumatology/Pediatrics, Santa Casa de Misericordia of Porto Alegre, Avenida Independência, 155, 90035-074 Porto Alegre, RS, Brazil

${ }^{3}$ Department of Orthopaedics and Traumatology/Hip Surgery, Santa Clara Hospital, Santa Casa de Misericordia of Porto Alegre, Reception 8, Rua Professor Annes Dias, 135, 90020-000 Porto Alegre, RS, Brazil

${ }^{4}$ Department of Physical Therapy, Santa Clara Hospital, Santa Casa de Misericordia of Porto Alegre, 2nd Floor, Rua Professor Annes Dias, 135, 90020-000 Porto Alegre, RS, Brazil

${ }^{5}$ Department of Physical Therapy, Federal University of Health Sciences of Porto Alegre, Rua Sarmento Leite, 245, 90050-170 Porto Alegre, RS, Brazil

Correspondence should be addressed to Carlos Roberto Schwartsmann; schwartsmann@gmail.com

Received 4 January 2014; Accepted 2 February 2014; Published 24 April 2014

Academic Editors: G. Babis and V. S. Nikolaou

Copyright ( 2014 Carlos Roberto Schwartsmann et al. This is an open access article distributed under the Creative Commons Attribution License, which permits unrestricted use, distribution, and reproduction in any medium, provided the original work is properly cited.

Objectives. To study the correlation between avascular necrosis and the demographics, time elapsed from fracture to surgery, quality of reduction, Garden classification, and the position of the screw following use of the dynamic hip screw (DHS) in the treatment of subcapital neck fractures. Methods. A prospective study of 96 patients with subcapital neck fractures was carried out in a faculty hospital. Patients underwent surgery with closed reduction and internal fixation with DHS. Results. There were 58\% male and $42 \%$ female patients, with a mean age of 53 years (+/-14). In terms of Garden classification, $60 \%$ were Garden IV, $26 \%$ were Garden III, and $14 \%$ were Garden II. Nonunion was observed in three cases (3\%) and was treated with valgus intertrochanteric osteotomy, in all cases leading to successful healing. Avascular necrosis was observed in $16 \%$ of patients. The positioning of the screw into the femoral head showed a significant correlation with necrosis. Conclusions. The incidence of necrosis in patients under the age of 50 years is twice as high as that in older patients. Displacement is a predictive factor regarding osteonecrosis and is associated with a high and anterior position of the screw in the femoral head. Level II of evidence. Study Type: therapeutic study.

\section{Introduction}

Surgical management of displaced subcapital fractures of the femoral neck continues to be challenging. Internal fixation, hemiarthroplasty, and total hip replacement could be considered as appropriate solutions.

For internal fixation, most orthopaedic surgeons choose either a dynamic hip screw (DHS) or multiple cannulated screws (MCS). Osteosynthesis with MCS fixation is a less invasive technique and reduces blood loss and soft tissue stripping [1-3]. With the use of DHS the screw-plate system achieves a more stable condition. Deneka et al. [4] published a biomechanical comparison of internal fixation techniques for the treatment of unstable basicervical femoral neck fractures. The results support the use of DHS. Its disadvantages are large skin incisions, more extensive soft tissue dissection, a greater need for blood transfusion, and a longer stay in hospital.

In a cross-sectional survey using a regressive analysis, Bhandari et al. [5] suggested that surgeons in Europe were more likely to indicate a DHS device over MCS than North 
American surgeons. Krastman et al. [3] defended the use of only two cannulated screws in nondisplaced femoral neck fractures but suggested DHS, as a more stable implant, for Garden III-IV fractures. Lee et al. [6], after reviewing 90 fractures, concluded that DHS showed a trend for an increased rate of overall success in elderly patients with nondisplaced femoral neck fracture compared with MCS.

There are few published reports focusing on DHS in the treatment of femoral intracapsular displaced neck fractures. Parker and Blundell [7] analysed the use of these implants for internal fixation. They reviewed 25 randomized trials and concluded that most studies have had an insufficient number of subjects to permit a valid comparison. Yih-Shiunn et al. [2] found overall failure in $15.9 \%$ of cases using MCS and in $2.5 \%$ of cases using DHS. Chen et al. [8], using DHS in extracapsular basicervical neck fractures, achieved union in $97.5 \%$ of their patients, with no cases of avascular necrosis and $1.7 \%$ of nonunion. Osteosynthesis not only has the potential to offer normal hip function after fracture consolidation but also has a relatively high rate of failure and complications in the form of nonunion, avascular necrosis, redisplacement, and so forth.

The purpose of the present study was to correlate the incidence of avascular necrosis following treatment with the DHS with patient demographics, time elapsed from the fracture to surgery, quality of reduction, Garden's classification [9], and the position of the screw in the head.

\section{Materials and Methods}

The present study prospectively evaluated 96 patients who had subcapital fractures of the femoral neck and were assigned to close reduction and internal fixation with DHS. Patients were operated on from 2000 to 2006. The inclusion criterion was subcapital fractures of the femoral neck and not tumoral ones, whereas exclusion criteria were bad quality X-rays pre- or postoperatively, more than a week since fracture, comminuted fractures, dislocated fractures classified as Garden III and IV in patients older than 75 years, rheumatoid arthritis and metabolic diseases (including osteoporosis Singh stage III or less), and incomplete records. We prospectively followed 128 patients, but 32 cases were excluded from the final analysis according to the exclusion criteria. The remaining 96 fractures were available for evaluation of functional results and complications. Four patients died but were still included, because they died 3 years, 4 years and 6 months, 8 years, and 7 years, respectively, after the onset of fracture.

All surgeries were performed by closed reduction, on a standard fracture table assisted by fluoroscopy. Minimal traction and rotation were applied in the first instance. If the fracture was incompletely reduced, small incremental increases in both traction and internal rotation were subsequently performed, checking the position after each adjustment [10]. A standard internal fixation with a $135^{\circ} \mathrm{DHS}$ was used, varying the number of screws and length of the plate as required.
Reduction was judged on both the anterior-posterior (AP) and lateral views. The junction of the convex femoral head and neck should produce an S-shaped curve in all planes [11]. A valgus reduction is inherently more stable, whereas a varus reduction is associated with a much higher risk of fixation failure [12]. What constitutes an acceptable reduction is debatable, and Arnold [13] recommended that there should be less than 20 degrees of posterior angulation to minimize the risk of fixation failure. Garden [14] described an alignment index to measure the quality of reduction, which was used in the present work.

Demographics, age at the onset of fracture, trauma mechanism, Garden's classification [9], associated fractures, time elapsed to surgery, American Society of Anaesthesiologists' (ASA) [15] criteria, Baumgaertner index, and hospital discharge were evaluated. The tip-apex distance (TAD) of all lag screws was measured, as described by Baumgaertner et al. [16], and the position of the screw in the head was classified in the anterior-posterior projection as high, middle, or low. The same was done in the lateral projection, classifying the position as anterior, central, or posterior. The criterion for good reduction was normal or slightly valgus alignment. Clinical results were assessed using the D’ Aubigné and Postel score [17].

The accepted definition of union was the development of a well-established trabecular pattern across the fracture site within 6 months following the date of injury. Avascular necrosis of the femoral head was diagnosed based on progressive pain with the classic mottled appearance, increasing radiodensity, segmental collapse, and degenerative changes. The Ficat staging system was used to evaluate the patients.

The Fisher method of statistical analysis was used to correlate all possible positions of the screw in the head with avascular necrosis.

\section{Results}

Table 1 presents the characteristics of the 96 patients. There were $56(58 \%)$ males and $40(42 \%)$ females with an overall mean age at the onset of fracture of 53 years $( \pm 14)$, ranging from 18 to 70 years. Seventy-eight patients (81\%) had experienced a simple fall. Sixteen (16\%) had fallen from height and three (3\%) were victims of automobile traffic trauma. The mean follow-up was 64.6 months.

With respect to Garden's classification for femoral neck fractures, 58 (60\%) were identified as Garden IV, 25 (26\%) were Garden III, and 13 (14\%) were Garden II. Fifty patients (52\%) had fractures of the right hip and 46 (48\%) of the left one. Eleven patients had associated fractures: three distal radius fractures, three rib fractures, two ankle fractures, two proximal humeral fractures, and one tibial shaft fracture.

Only one (1\%) patient was operated on in the first 24 hours. Fifty-five (57\%) patients were operated on between 24 to 72 hours after fracture. Forty (42\%) were operated on after 72 hours. When considering clinical conditions, 68 (71\%) were considered ASA I (normal healthy) and 28 (29\%) were ASA II (mild systemic disease). 
TABLE 1: Demographics and characteristics of evaluated cases.

\begin{tabular}{lcccc}
\hline Characteristic & Number & $(\%)$ & Osteonecrosis & $(\%)$ \\
\hline Sex & & & & \\
$\quad$ Male & 56 & 58 & 9 & 9 \\
$\quad$ Female & 40 & 42 & 7 & 7 \\
Age group & & & & \\
$\quad$ 18-40 & 21 & 22 & 4 & 4 \\
41-50 & 25 & 26 & 6 & 6 \\
51-60 & 18 & 19 & 4 & 4 \\
$\quad$ 61-70 & 32 & 33 & 2 & 2 \\
Garden grade & & & & \\
$\quad$ II & 13 & 14 & - & - \\
III & 25 & 26 & 4 & 4 \\
IV & 58 & 60 & 12 & 13 \\
Time of surgery & & & & \\
$\quad<24$ hours & 1 & 1 & - & - \\
24-72 hours & 55 & 57 & 7 & 7 \\
$\quad>72$ hours & 40 & 42 & 9 & 9 \\
Reduction (AP view) & & & & \\
$\quad$ Neutral & 61 & 64 & 11 & 11 \\
Valgus & 33 & 34 & 5 & 5 \\
$\quad$ Varus & 2 & 2 & - & - \\
Reduction (lateral view) & & & & \\
$\quad$ Neutral & 69 & 72 & 10 & 10 \\
$\quad$ Anterior & 19 & 20 & 4 & 4 \\
$\quad$ Posterior & 8 & 8 & 2 & 2 \\
\hline
\end{tabular}

The DHS plate was fixed with two screws in five patients (5\%), while three screws were used in 61 patients (64\%), and four screws in 30 patients (31\%). Good reduction was obtained in 94 (98\%) of the patients, which means normal or slightly valgus reduction. The average hospital discharge was 9 days.

The greatest penetration into the femoral head for the lag screw of the DHS was $66 \mathrm{~mm}$, whereas the least penetration was $31 \mathrm{~mm}$, with an average of $42.3 \mathrm{~mm}$. The mean TAD was $16 \mathrm{~mm}$ (ranging from 11 to $24 \mathrm{~mm}$ ).

A satisfactory union was achieved in 80 patients, with a failure rate of about $20 \%$. Three patients failed to show union after 6 months (3\%) and presented criteria justifying surgical reintervention. In these cases, the radiographs showed no radiological signs of consolidation, with resorption of the fracture, pain, and synthesis failure. All of these nonunions were treated with a valgus intertrochanteric osteotomy, all of them achieving successful healing.

Sixteen cases of avascular necrosis were observed (16\%), ten of which were classified as Ficat 3 and six as Ficat 4 . Most of our patients $(58 \% ; 56 / 96)$ were operated on in the first 72 hours. However, a substantial number was operated on after 72 hours $(42 \% ; 40 / 96)$. The percentage of osteonecrosis in the latter group was $23 \%$ (9/40), being almost double that of the former $(13 \%$; $7 / 56)$. The average age of these patients was 45 years. The latest diagnosis was 5.6 years after the fracture. Four fractures healed with shortening of the femoral neck of less than $15 \mathrm{~mm}$.
We also analysed the screw position based on all nine possibilities presented in Figure 1 for the AP and lateral projections (see also Table 2) and correlated them with osteonecrosis. The most frequent position was middle (AP) and central (lateral view), as observed in 47 patients (49\%), with four cases of osteonecrosis $(9 \% ; 4 / 47)$. The combination high (AP) and anterior (lateral) was observed in eight fractures $(8 \%)$ and five of these patients developed osteonecrosis $(63 \% ; 5 / 8)$. This was the only statistically significant association between screw placement and osteonecrosis $(p=0.0029$, using Fisher's correction).

Regarding the D' Aubigné and Postel score, sixty patients (63\%) scored 18 points, 18 (19\%) scored 17 points, and 18 (19\%) scored less than 17 points.

We correlated age, gender, side, time elapsed until surgery, Garden's classification, and quality of reduction with avascular necrosis and no statistical differences were found, but when we analysed the position of the screw in the femoral head we found a significant correlation between necrosis and the high, anterior position $(p=0.003)$.

\section{Discussion}

The treatment of displaced femoral neck fractures has been debated for many years. The main question during decision making is whether to fix or replace the femoral neck. Many recently published papers have shown that a primary total hip replacement is superior to internal fixation for the treatment of displaced femoral neck fractures when performed in a relatively healthy and mentally competent elderly patient $[5,7,18-20]$. However, the optimal treatment for a young or adult patient under 70 years old is controversial, as the younger the patient is, the more the orthopaedic surgeon is obliged to pursue internal fixation.

There are many factors that could influence the decision: the preinjury functional status regarding gait, mental ability, and habitat, but the most important consideration is probably the difference between chronological and biological age. Criticisms against internal fixation are due to its association with high rates of failure due to loss of fixation, osteonecrosis, and nonunion. Nevertheless, when a femoral head heals over the neck, the patient has the chance of regaining his physiologically normal hip.

Lu-Yao et al. [21] published a meta-analysis of 106 published reports and concluded that the rate of loss of fixation or reduction after open reduction and internal fixation (ORIF) is about $16 \%$ (9-27\%), which is significantly higher than the risk of dislocation after hemiarthroplasty (2\%) or total hip replacement. Tronzo [22] identified more than 100 different available implants for ORIF of femoral neck fractures. However, if a surgeon chooses ORIF, he basically must decide between two consecrated techniques: multiple cannulated screws (MCS) or a dynamic hip screw (DHS).

Several studies have attempted to identify predictive factors of failure in femoral neck fracture treatment. There is little agreement among these studies regarding which fractures are more likely to fail because they analysed both displaced and nondisplaced fractures, different clinical and 


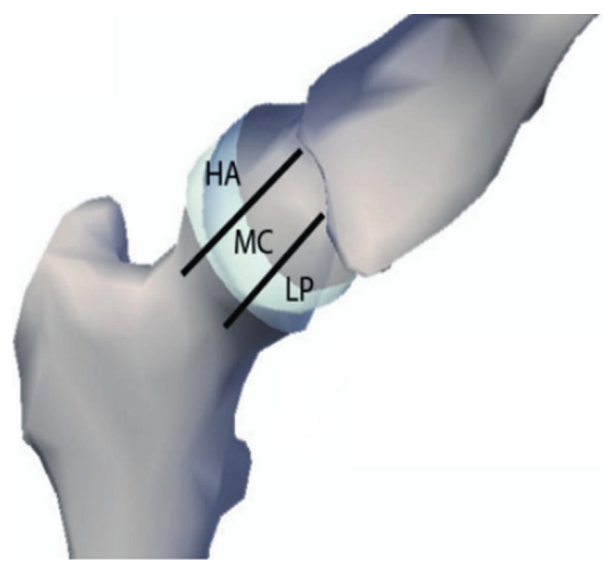

(a)

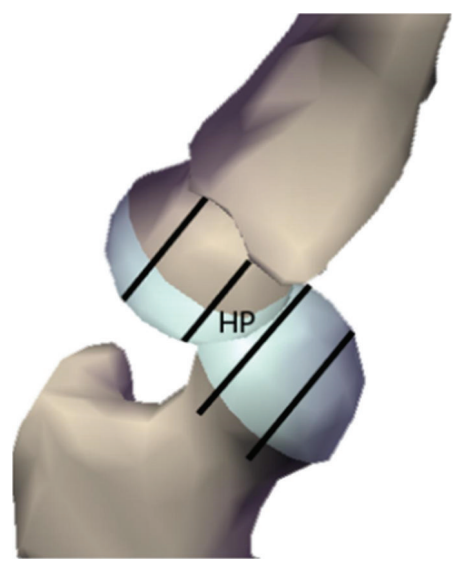

(b)

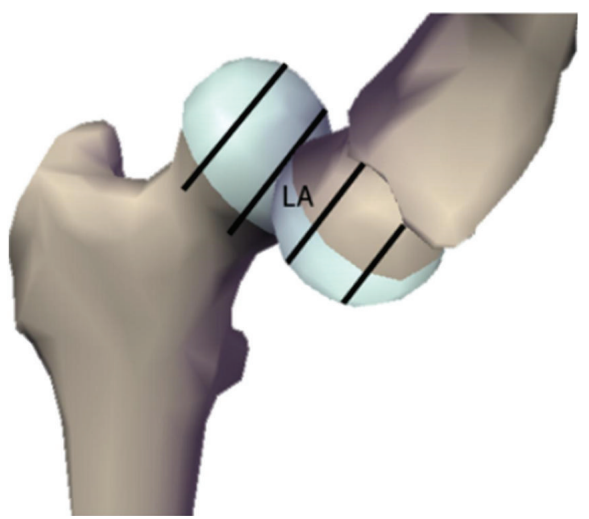

(c)

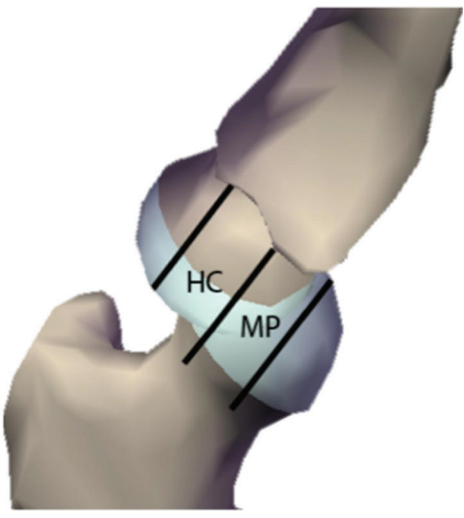

(d)

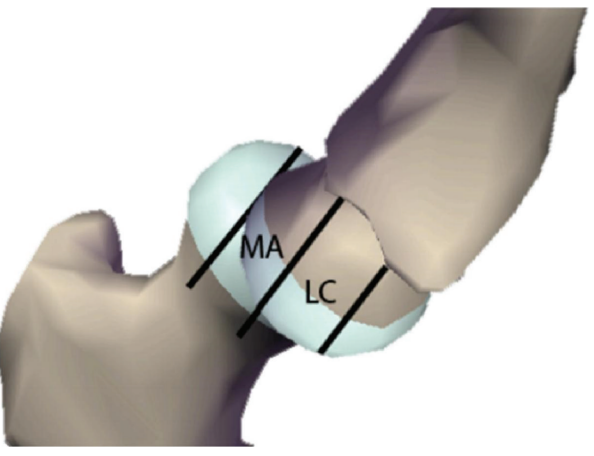

(e)

FIGURE 1: Avascular necrosis versus screw placement on the femoral head. $\mathrm{H}=$ high; $\mathrm{M}=$ middle; $\mathrm{L}=$ low; $\mathrm{A}=$ anterior; $\mathrm{P}=$ posterior; $\mathrm{C}=$ centre.

TABLE 2: Avascular necrosis versus screw placement on the femoral head.

\begin{tabular}{lccccc}
\hline $\begin{array}{l}\text { Screw position in the } \\
\text { femoral head }\end{array}$ & Number & $(\%)$ & Necrosis & $(\%)$ & $p$ \\
\hline H-A & 8 & 8 & 5 & 5 & 0.003 \\
H-C & 8 & 8 & 3 & 3 & 0.126 \\
H-P & 1 & 1 & 0 & - & - \\
M-A & 3 & 3 & 1 & 1 & 0.425 \\
M-C & 47 & 49 & 4 & 4 & 0.054 \\
M-P & 5 & 5 & 1 & 1 & 0.607 \\
L-A & 2 & 2 & 1 & 1 & 0.307 \\
L-C & 11 & 12 & 1 & 1 & 0.684 \\
L-P & 11 & 12 & 0 & - & - \\
\hline Total & 96 & 100 & 16 & 16 & \\
\hline
\end{tabular}

H: high; M: middle; L: low; A: anterior; P: posterior; C: central.

radiological factors, different implants for internal fixation, different weight-bearing times, and so forth.

The results of osteosynthesis in young patients are debatable by presenting a considerable complication rate. However, there is little doubt that the main complication is the occurrence of osteonecrosis. Many variables have been hypothesized to be associated with this complication after femoral neck fractures. The literature does not support differences regarding gender, but high rates of nonunion and avascular necrosis are more common in young adult patients. Various explanations have been elaborated, including high energy trauma and its correlation with dislocated fractures in the young adult. The rate of osteonecrosis ranges from $12 \%$ to $86 \%$ [23-27]. Gautam et al. [26], while operating on 25 young adults on an ordinary table using the traditional WatsonJones approach, described three cases of osteonecrosis (12\%). Protzman and Burkhalter [23], reviewing 22 fractures in young patients aged under 40 years, found $86 \%$ of necrosis. We divided our cases according to age into two main groups: under 50 years ( 46 fractures) and over 50 years (50 fractures). The incidence of osteonecrosis was $22 \%(10 / 46)$ in the first group and $12 \%(6 / 50)$ in the second one. No statistical difference was found.

Another topic of discussion is the amount of initial fracture displacement. The most useful classification was proposed by Garden [9]. Basically, the author divided the fractures into not displaced (Garden I and II) or displaced (Garden III and IV). In our study, only 13 fractures were considered nondisplaced (14\%) and 83 were considered 
displaced (86\%). We did not find any osteonecrosis in the first group, while there was an incidence of 19\% (16/83) in the second group $(p=0.12)$.

Conn and Parker [28], when evaluating 375 nondisplaced fractures, observed necrosis in 4\% (15/375). Yih-Shiunn et al. [2] reviewed 84 cases of nondisplaced fractures and found an incidence of about $10 \%(8 / 84)$. Haidukewych [25] found $14 \%$ (3/22) and Nikolopoulos et al. [29] found 19.5\% (9/46).

When only displaced fractures are taken into consideration, this complication is more frequent. In an extensive meta-analysis, Lu-Yao et al. [21] found a 16\% rate of osteonecrosis, and Blomfeldt et al. [19] recorded 19\% of cases with necrosis after 48 months. Majerníček et al. [30] observed $13.4 \%(9 / 64)$ after a minimum of 5 years of followup. Haidukewych [25] found 27\% (14/51), and Nikolopoulos et al. [29] found $39.4 \%$ in displaced fractures (15 out of 38) after a mean follow-up of 4.7 years. Kaplan et al. [31] recently performed a study comparing open and closed reduction with internal fixation. Avascular necrosis was more common in displaced fractures $(30.3 \% ; 10 / 33)$.

Another controversial issue is the timing of surgery. Barnes et al. [32], in their historical paper, describe a longterm follow-up of 1503 subcapital fractures and conclude that the mortality rate increased when operation was delayed beyond 3 days following injury, but no significant difference was found in necrosis or late segmental collapse when delaying the operation up to 1 week. Most of our patients were operated on in the first 72 hours $(58 \% ; 56 / 96)$. However, a substantial number was operated on after 72 hours: $42 \%$ (40/96). The percentage of osteonecrosis in the latter group was $23 \%(9 / 40)$, being almost double that of the former: $13 \%$ (7/56). This suggests that it could be worse to fix the fracture more than 72 hours after the fracture's onset, but no statistical difference was found between operating earlier or later in terms of necrosis $(p=0.41)$.

Advocates of early surgery suggest that prompt reduction can produce an "unkinking" of the proximal femoral vessels, thus leading to intracapsular decompression, restoring the blood flow to the femoral head and minimizing the risk of necrosis $[33,34]$. Other studies confirm that early surgery may decrease the rate of femoral head osteonecrosis [35-38]. On the contrary, several studies have reported no difference in the rate of osteonecrosis with more than a 24-hour delay.

Upadhyay et al. [39] performed a prospective and randomized study of 102 patients, comparing open and closed reduction with internal fixation. Time to surgery did not affect the development of osteonecrosis. In a retrospective review of 73 femoral neck fractures Haidukewych et al. [40] reported the same outcome. He found a rate of osteonecrosis of $23 \%$. He reported that $25 \%$ (17/73) of femoral neck fractures that were treated within 24 hours of diagnosis developed osteonecrosis. Twenty percent of the fractures that were internally fixed after 24 hours developed the same complication $(4 / 20)$.

The quality of fracture reduction or postreduction malalignment is another topic of discussion. Most authors agree that the best position is anatomical reduction or a slight valgus $[6,32,38]$. In our study, of the 96 fractures we considered as a good quality reduction, necrosis occurred in 16 cases
(16\%). Only two patients had what we considered a slight varus reduction. Neither of these developed osteonecrosis.

The controversy about screw position in the femoral head has remained unresolved until today. The main point of discussion concerns central versus posterior-inferior screw placement. There is a consensus that the anterior-superior position should be avoided $[8,16,32]$. Barnes et al. [32] were probably the first to call attention to the fact that a nail or screw placed too superior and anterior in the femoral head was associated with a considerable failure rate in women (37\% in Garden III and 52\% in Garden IV). However, the present research demonstrates that the incidence of osteonecrosis is correlated with the position of the screw in the femoral head. Since Barnes et al.s study [32], there has been no paper in the literature regarding the position of the screw in relation to avascular necrosis. They were the first to call attention to the association between the anterior-superior position of the screw and worse results. The authors recognize that the present study has a nonrandomized nature, absence of control group, and a small number of patients, but we realize that our findings, although preliminary, are similar in relation to necrosis when comparing to the literature.

\section{Conclusions}

No statistically significant association was found between gender, time elapsed to surgery, quality of reduction and fracture displacement, and the onset of avascular necrosis of the femoral head. The incidence of osteonecrosis in patients under 50 years was twofold higher than in patients over 50 years of age, but this difference was not statistically significant. The fracture's displacement is a predictive factor regarding osteonecrosis. The incidence of osteonecrosis was associated with the "high and anterior" position of the screw in the femoral head.

\section{Conflict of Interests}

The authors declare no conflict of interests.

\section{References}

[1] J. E. Madsen, "Treatment of displaced intracapsular hip fractures in older patients," British Medical Journal, vol. 340, p. c2810, 2010.

[2] L. Yih-Shiunn, H. Chien-Rae, and L. Wen-Yun, "Surgical treatment of undisplaced femoral neck fractures in the elderly," International Orthopaedics, vol. 31, no. 5, pp. 677-682, 2007.

[3] P. Krastman, R. P. van den Bent, P. Krijnen, and I. B. Schipper, "Two cannulated hip screws for femoral neck fractures: treatment of choice or asking for trouble?" Archives of Orthopaedic and Trauma Surgery, vol. 126, no. 5, pp. 297-303, 2006.

[4] D. A. Deneka, P. T. Simonian, C. J. Stankewich, D. Eckert, J. R. Chapman, and A. F. Tencer, "Biomechanical comparison of internal fixation techniques for the treatment of unstable basicervical femoral neck fractures," Journal of Orthopaedic Trauma, vol. 11, no. 5, pp. 337-343, 1997.

[5] M. Bhandari, P. J. Devereaux, M. F. Swiontkowski et al., "Internal fixation compared with arthroplasty for displaced fractures of 
the femoral neck: a meta-analysis," The Journal of Bone and Joint Surgery A, vol. 85, no. 9, pp. 1673-1681, 2003.

[6] Y.-S. Lee, S.-H. Chen, Y.-H. Tsuang, H.-L. Huang, T.-Y. Lo, and C.-R. Huang, "Internal fixation of undisplaced femoral neck fractures in the elderly: a retrospective comparison of fixation methods," Journal of Trauma: Injury, Infection and Critical Care, vol. 64, no. 1, pp. 155-162, 2008.

[7] M. J. Parker and C. Blundell, "Choice of implant for internal fixation of femoral neck fractures. Meta-analysis of 25 randomised trials including 4925 patients," Acta Orthopaedica Scandinavica, vol. 69, no. 2, pp. 138-143, 1998.

[8] W.-C. Chen, S.-W. Yu, I.-C. Tseng, J.-Y. Su, Y.-K. Tu, and W.-J. Chen, "Treatment of undisplaced femoral neck fractures in the elderly," Journal of Trauma, vol. 58, no. 5, pp. 1035-1039, 2005.

[9] R. S. Garden, "Stability and union in subcapital fractures of the femur," Journal of Bone and Joint Surgery B, vol. 46, pp. 630-647, 1964.

[10] J. Keating, "Femoral neck fractures," in Rockwood and Green's Fractures in Adults, R. W. Bucholz, J. D. Heckman, C. M. CourtBrown, and P. Tornetta III, Eds., Lippincott Williams \& Wilkins, 7th edition, 2010.

[11] J. D. Lowell, "Results and complications of femoral neck fractures," Clinical Orthopaedics and Related Research, vol. 152, pp. 162-172, 1980.

[12] B. Barnes and K. Dunovan, "Functional outcomes after hip fracture," Physical Therapy, vol. 67, no. 11, pp. 1675-1679, 1987.

[13] W. D. Arnold, "The effect of early weight-bearing on the stability of femoral neck fractures treated with Knowles pins," The Journal of Bone and Joint Surgery A, vol. 66, no. 6, pp. 847-852, 1984.

[14] R. S. Garden, "Malreduction and avascular necrosis in subcapital fractures of the femur," Journal of Bone and Joint Surgery B, vol. 53, no. 2, pp. 183-197, 1971.

[15] American Socitey of Anesthesiologists, "New classification of physical status," Anesthesiology, vol. 24, p. 111, 1963.

[16] M. R. Baumgaertner, S. L. Curtin, D. M. Lindskog, and J. M. Keggi, "The value of the tip-apex distance in predicting failure of fixation of peritrochanteric fractures of the hip," The Journal of Bone and Joint Surgery A, vol. 77, no. 7, pp. 1058-1064, 1995.

[17] R. M. D’ Aubigné and M. Postel, "Function al results of hip arthroplasty with acrylic prosthesis," The Journal of Bone and Joint Surgery A, vol. 36, no. 3, pp. 451-475, 1954.

[18] J.-E. Gjertsen, T. Vinje, L. B. Engesæter et al., "Internal screw fixation compared with bipolar hemiarthroplasty for treatment of displaced femoral neck fractures in elderly patients," The Journal of Bone and Joint Surgery A, vol. 92, no. 3, pp. 619-628, 2010.

[19] R. Blomfeldt, H. Törnkvist, S. Ponzer, A. Söderqvist, and J. Tidermark, "Comparison of internal fixation with total hip replacement for displaced femoral neck fractures: randomized, controlled trial performed at four years," The Journal of Bone and Joint Surgery A, vol. 87, no. 8, pp. 1680-1688, 2005.

[20] J. A. Lowe, B. D. Crist, M. Bhandari, and T. A. Ferguson, "Optimal treatment of femoral neck fractures according to patient's physiologic age: an evidence-based review," Orthopedic Clinics of North America, vol. 41, no. 2, pp. 157-166, 2010.

[21] G. L. Lu-Yao, R. B. Keller, B. Littenberg, and J. E. Wennberg, "Outcomes after displaced fractures of the femoral neck. A meta-analysis of one hundred and six published reports," The Journal of Bone and Joint Surgery A, vol. 76, no. 1, pp. 15-25, 1994.
[22] R. G. Tronzo, "Symposium on fractures of the hip. Special considerations in management," Orthopedic Clinics of North America, vol. 5, no. 3, pp. 571-583, 1974.

[23] R. R. Protzman and W. E. Burkhalter, "Femoral neck fractures in young adults," The Journal of Bone and Joint Surgery A, vol. 58, no. 5, pp. 689-695, 1976.

[24] D. K. Dedrick, J. R. Mackenzie, and R. E. Burney, "Complications of femoral neck fracture in young adults," Journal of Trauma, vol. 26, no. 10, pp. 932-937, 1986.

[25] G. J. Haidukewych, "Salvage of failed treatment of femoral neck fractures," Instructional Course Lectures, vol. 58, pp. 83-90, 2009.

[26] V. K. Gautam, S. Anand, and B. K. Dhaon, "Management of displaced femoral neck fractures in young adults (a group at risk)," Injury, vol. 29, no. 3, pp. 215-218, 1998.

[27] R. I. Davidovitch, C. J. Jordan, K. A. Egol, and M. S. Vrahas, "Challenges in the treatment of femoral neck fractures in the nonelderly adult," The Journal of Trauma, vol. 68, no. 1, pp. 236242, 2010.

[28] K. S. Conn and M. J. Parker, "Undisplaced intracapsular Hip fractures: results of internal fixation in 375 patients," Clinical Orthopaedics and Related Research, no. 421, pp. 249-254, 2004.

[29] K. E. Nikolopoulos, S. A. Papadakis, K. T. Kateros et al., "Longterm outcome of patients with avascular necrosis, after internal fixation of femoral neck fractures," Injury, vol. 34, no. 7, pp. 525528, 2003.

[30] M. Majerníček, P. Dungl, J. Kolman, T. Malkus, and J. Vaculík, "Osteosynthesis of intracapsular femoral neck fractures by dynamic hip screw (DHS) fixation," Acta Chirurgiae Orthopaedicae et Traumatologiae Cechoslovaca, vol. 76, no. 4, pp. 319-325, 2009.

[31] T. Kaplan, B. Akesen, B. Demirağ, S. Bilgen, and K. Durak, "Comparative results of percutaneous cannulated screws, dynamic compression type plate and screw for the treatment of femoral neck fractures," Turkish Journal of Trauma \& Emergency Surgery, vol. 18, no. 1, pp. 65-70, 2012.

[32] R. Barnes, J. T. Brown, R. S. Garden, and E. A. Nicoll, "Subcapital fractures of the femur: a prospective review," The Journal of Bone and Joint Surgery B, vol. 58, no. 1, pp. 2-24, 1976.

[33] W. M. Harper, M. R. Barnes, and P. J. Gregg, "Femoral head blood flow in femoral neck fractures. An analysis using intraosseous pressure measurement," The Journal of Bone and Joint Surgery B, vol. 73, no. 1, pp. 73-75, 1991.

[34] B. Strömqvist, L. T. Nilsson, N. Egund, K.-G. Thorngren, and H. Wingstrand, "Intracapsular pressures in undisplaced fractures of the femoral neck," The Journal of Bone and Joint Surgery B, vol. 70, no. 2, pp. 192-194, 1988.

[35] C. Gerber, J. Strehle, and R. Ganz, "The treatment of fractures of the femoral neck," Clinical Orthopaedics and Related Research, no. 292, pp. 77-86, 1993.

[36] C. Zetterberg, S. Elmerson, and G. B. J. Andersson, "Epidemiology of hip fractures in Goteborg, Sweden, 1940-1983," Clinical Orthopaedics and Related Research, vol. 191, pp. 43-52, 1984.

[37] J. Manninger, K. G. Kazar, F. G. Fekete et al., "Avoidance of avascular necrosis of the femoral head, following fractures of the femoral neck, by early reduction and internal fixation," Injury, vol. 16, no. 7, pp. 437-448, 1985.

[38] R. Jain, M. Koo, H. J. Kreder, E. H. Schemitsch, J. R. Davey, and N. N. Mahomed, "Comparison of early and delayed fixation of subcapital hip fractures in patients sixty years of age or less," The Journal of Bone and Joint Surgery A, vol. 84, no. 9, pp. 1605-1612, 2002. 
[39] A. Upadhyay, P. Jain, P. Mishra, L. Maini, V. K. Gautum, and B. K. Dhaon, "Delayed internal fixation of fractures of the neck of the femur in young adults," The Journal of Bone and Joint Surgery B, vol. 86, no. 7, pp. 1035-1040, 2004.

[40] G. J. Haidukewych, W. S. Rothwell, D. J. Jacofsky, M. E. Torchia, and D. J. Berry, "Operative treatment of femoral neck fractures in patients between the ages of fifteen and fifty years," The Journal of Bone and Joint Surgery A, vol. 86, no. 8, pp. 1711-1716, 2004. 


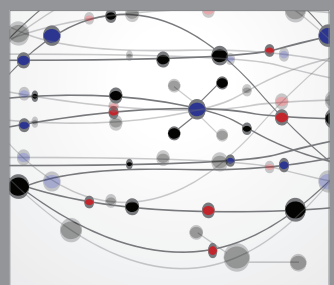

The Scientific World Journal
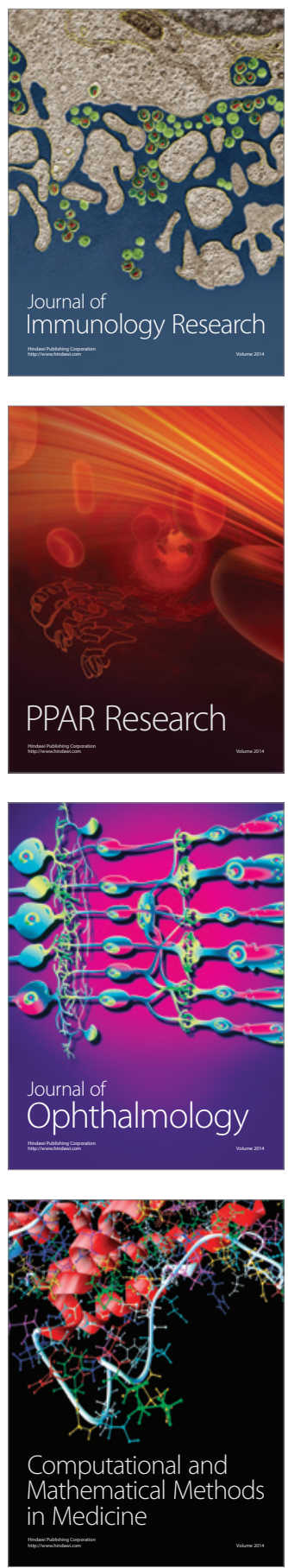

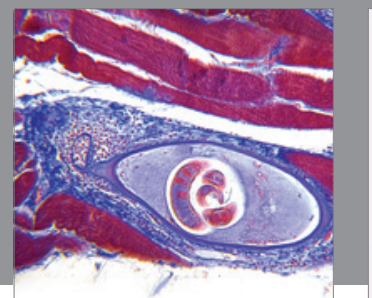

Gastroenterology

Research and Practice
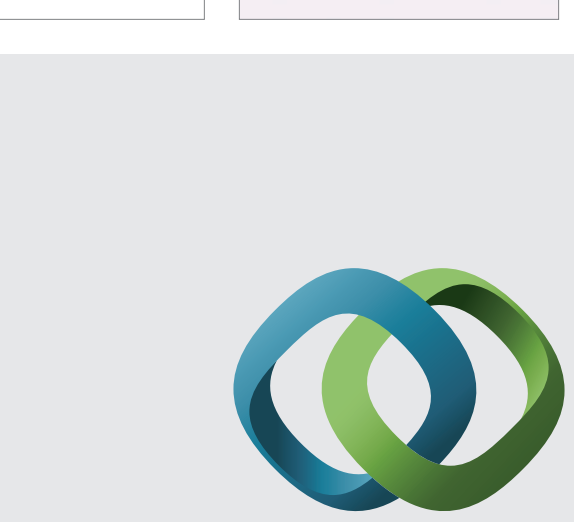

\section{Hindawi}

Submit your manuscripts at

http://www.hindawi.com
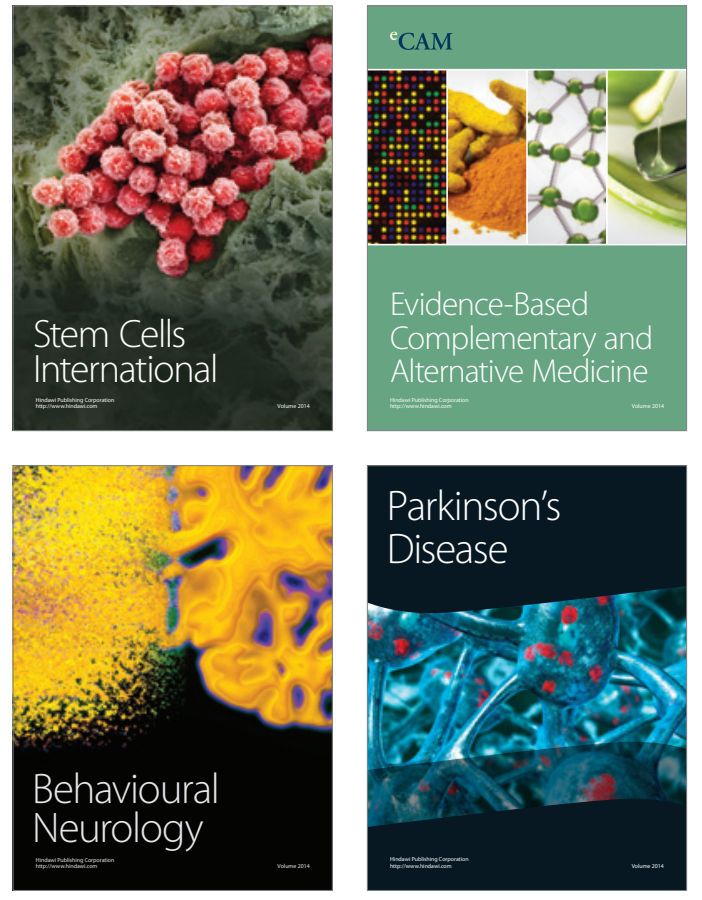
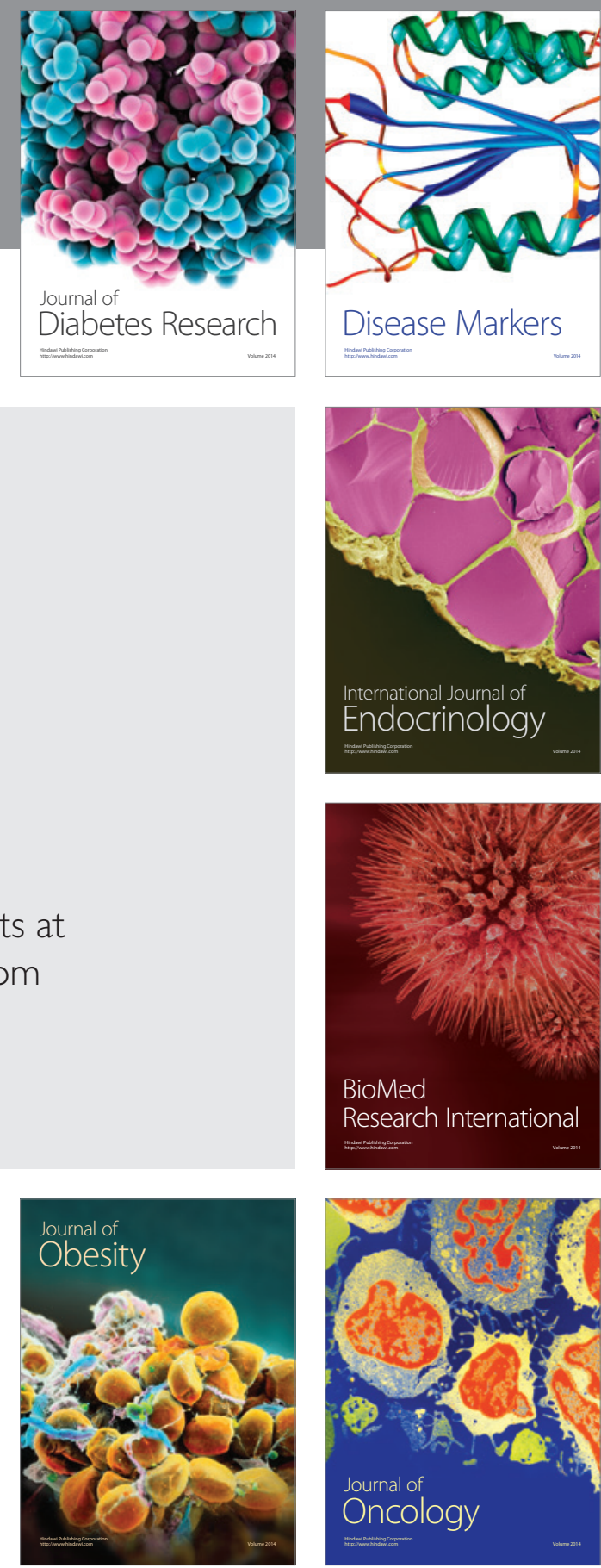

Disease Markers
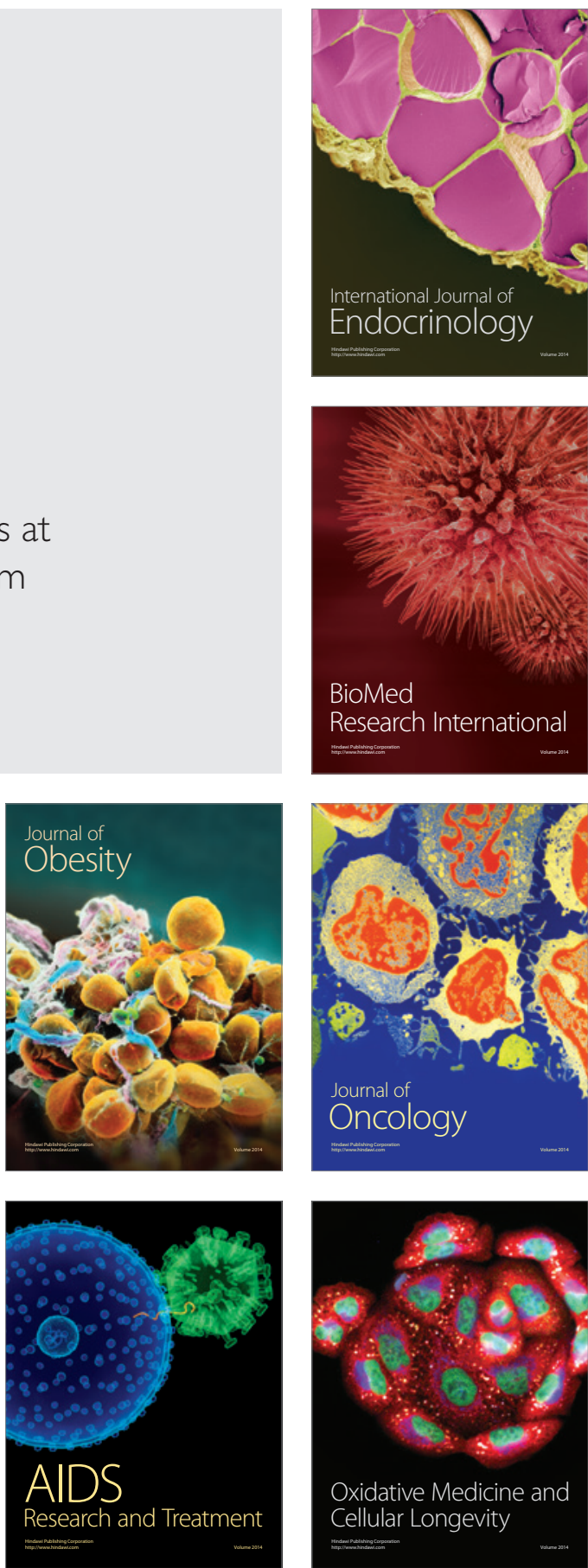